\title{
Short Fatigue Crack Behavior of LZ50 Axle Steel under Rotating-Bending Cyclic Loading
}

\author{
B. Yang, ${ }^{1}$ S. Dai, Y. Y. Wu, Z. Liao, S. Liang, S. N. Xiao \\ State Key Laboratory of Traction Power, Southwest Jiaotong University, Chengdu, China \\ 1.yb@swjtu.cn
}

The short fatigue short crack replica tests using LZ50 axle steel hourglass-shaped specimens of were carried out under rotating-bending cyclic load. Seven sets of effective test data were obtained. The analysis demonstrated that short fatigue cracks generally originate in ferrite grains or on their boundaries, and then short cracks start propagating, which is strongly influenced by the microstructure of the material. The crack growth rate increases serratically, followed by its decrease double-fold because of the limit of ferrite grain boundaries and the banded pearlite structure. Based on the three principles of the best fit, which include the overall fitting effect, correlation with fatigue physics, and safety of residual strength prediction, the statistical evolution of the dominant effective short fatigue crack length and life share were analyzed. The statistical results show that the minimum value distribution exhibit the best fit of the dominant effective fatigue short crack length and the life share. The short fatigue crack growth model, which includes various microstructure barriers, provides a good fitting result and reflects the cyclic effect of the microstructure on the short fatigue crack behavior.

Keywords: fatigue, short crack, rotating-bending load, LZ50 axle steel.

Introduction. Fatigue and fracture are the main causes of the failure of engineering structures and components [1]. The prediction of the behavior of fatigue cracks by the linear elastic fracture mechanics (LEFM) is limited, since it fails to describe the observed propagation patterns of short fatigue cracks [2]. Numerous experimental results show that for components with a smooth surface, the initiation and growth of short fatigue cracks occupy over $80 \%$ of their total fatigue life [3]. Therefore, it is of great importance to study the initiation and growth of short fatigue cracks, which has important engineering significance for the accurate prediction the component fatigue life values.

The axle is the key bearing component of locomotives and vehicles, which is subjected to a number of complex stresses, such as rotating-bending and impact during running so that the fatigue cracking is the main form of failure. With the improvement of science and technology, the passenger and freight volume of railway vehicles is increasing as well as the running speed. Consequently, the alternating loads of axles are becoming more and more complicated and seriously influence the traffic safety. In present study, the behavior of short fatigue crack for LZ50 axle steel under rotating-bending load is studied. Based on the replica tests and observation data from laser scanning confocal microscope, there is a good understanding for the behavior of short fatigue crack. The specific work is as follows:

(i) the short fatigue crack replica tests under rotating-bending load have carried out and the process of short fatigue crack initiation and growth under rotating-bending load have been revealed by the analysis of the experimental results;

(ii) the statistical evolution of the dominant effective fatigue short crack (DESFC) scale and life share for LZ50 axle steel under rotating-bending load has been analyzed;

(iii) based on the short fatigue crack growth model which includes various microstructure barriers, the short crack growth rate under rotating-bending load is fitted and compared with the experimental data. 


\section{Experimental Details.}

1.1. Materials and Specimens. The specimens are made from LZ50 axle steel which is originated from a RE2B type axle. The originally cylindrical specimens were processed to obtain the hourglass shape, as shown in Fig. 1. The minimum diameter of the specimen was $6 \mathrm{~mm}$ and the intermediate part was polished to reduce the surface roughness. The heat-treatment conditions were as follows: normalizing heating for $2 \mathrm{~h}$ under 860 and $800^{\circ} \mathrm{C}$, tempering for $1.5 \mathrm{~h}$ under $570^{\circ} \mathrm{C}$ according to the Chinese standard [4]. The chemical composition (wt.\%) of LZ50 axle steel was $0.47 \mathrm{C}, 0.78 \mathrm{Mn}, 0.26 \mathrm{Si}, 0.15 \mathrm{Cu}$, $0.028 \mathrm{Ni}, 0.021 \mathrm{Al}, 0.02 \mathrm{Cr},<0.014 \mathrm{P}$, and $<0.007 \mathrm{~S}$. The mechanical properties at room temperature were as follows: $209.750 \mathrm{GPa}$ for elastic modulus, $628.96 \mathrm{MPa}$ for tensile strength, $329.94 \mathrm{MPa}$ for yield strength, $24.41 \%$ for elongation, $41.92 \%$ for reduction of area, and $44 \mathrm{~J} / \mathrm{cm}^{2}$ for impact toughness.

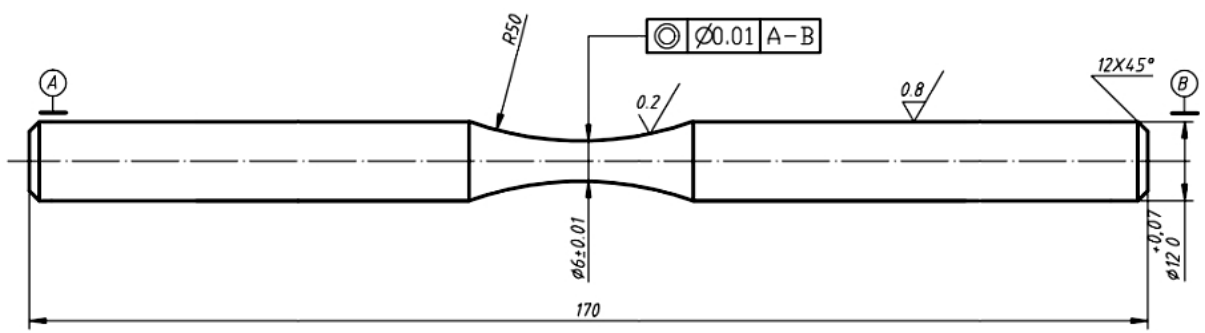

Fig. 1. Schematic of shape and dimension of the specimen (unit: $\mathrm{mm}$ ).

1.2. Metallographic Tests. The metallographic tests of LZ50 steel specimens were conducted, which showed its composition, including ferrite and lamellar pearlite (Fig. $2 \mathrm{~b}$ ). Due to forging used in the process of material smelting, the pearlite had a banded structure (Fig. 2a). The measured equivalent diameters of ferrite and pearlite were 13.12 and $14.83 \mu \mathrm{m}$, while the average spacing of the banded pearlite structure was $64.59 \mu \mathrm{m}$.

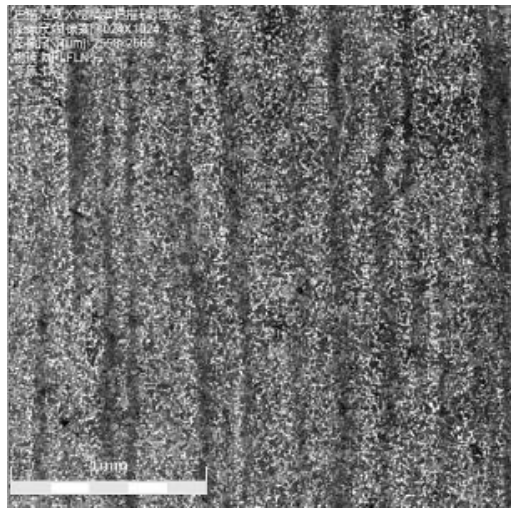

a

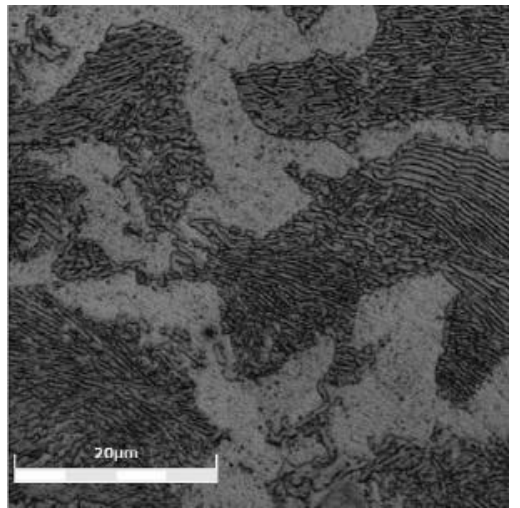

$\mathrm{b}$

Fig. 2. Low (a) and high (b) metallographs of LZ50 axle steel.

1.3. Replica Tests. All replica tests were performed using a PQ-6 rotating bending fatigue machine under sine loading wave with the loading frequency of $50 \mathrm{~Hz}$. The maximum nominal stress was controlled to be $310 \mathrm{MPa}$ and the stress ratio was equal to $R=-1$ [5]. Each test involved one specimen, which was evenly engraved with a depth of 
about $5 \mu \mathrm{m}$ by longitudinal scratches in the middle of the smooth part. These scratches were used as marks, which would not affect the specimen life, but were instrumental in the short crack detection and location by the microscopic observation [6-9]. Installing the specimen on the machine and then turning on the power, the replica test started. In the process of loading, the test would be interrupted at a predetermined cycle number. Then, cellulose acetate film softened with methyl acetate was pasted on the specimen middle surface. Once the methyl acetate was completely evaporated, the film, which reflected the appearance morphology of the specimen surface, was carefully removed with tweezers. Finally, the dried film was placed between two glass plates. The predetermined cycle numbers of tests were as follows: $0-0.2 w-0.5 w-1 w-3 w-5 w-10 w-15 w-20 w-25 w-30 w-$ $35 w-40 w$-fracture (where $w$ represents $10^{4}$ cycles).

Eventually, seven effective specimens were obtained and their replicas were examined step-by-step, according to the reverse observation method using Olympus OSL4100 laser scanning confocal microscope, to investigate the behavior of short fatigue cracks under rotating-bending cyclic load. The fatigue fracture surface features (striations) were observed using the scanning electron microscope (SEM).

\section{Description of Short Crack Behavior.}

2.1. Observation of Typical Specimen. Take the typical specimen B-2 as an example, the fatigue life of B-2 is 363,726 cycles and there are a total of 12 replica films. Figure 3 shows the growth of short cracks for B-2 specimen. Based on the "effective short fatigue criterion" proposed by Zhao [10, 11], the behavior of short fatigue crack under rotating-bending cyclic load is described below ( $C$ is effective short fatigue crack and $F$ is ineffective short fatigue crack):

(a) $N=0$ cycles, at which point the specimen bears no load, so there are few surface defects, except for some vertical lines, which are very shallow and parallel with each other. This is because the polishing process will produce a pattern in the specimen surface by pressure and form the reflection of these lines like traces.

(b) $N=30,013$ cycles, short fatigue cracks $C 1, C 2$, and $F 1$ were nucleated in the ferrite grain. The lengths of $C 1$ and $C 2$ are about $20 \mu \mathrm{m}$, while the length of $F 1$ is slightly smaller ( of about $7 \mu \mathrm{m}$ ). As compared with the equivalent diameters of ferrite (between 4.41 and $27.61 \mu \mathrm{m}$, and the average is $13.12 \mu \mathrm{m}$ ) measured previously, it is found that lengths of these three short cracks are equivalent to the equivalent diameters of ferrite.

(c) $N=150,012$ cycles, the crack tip of $C 1$ breaks through the ferrite grain boundary and begins to grow at both ends, reaching a length of $57.970 \mu \mathrm{m}$, while $C 2$ and $F 1$ are still limited within the ferrite grain and controlled by their respective grain.

(d) $N=200,013$ cycles, $C 1$ begins to grow quickly to a length of $101.922 \mu \mathrm{m}$ which is close to the spacing of pearlite banded structure (between 47.58 and $129.66 \mu \mathrm{m}$, and the average is $64.5 \mu \mathrm{m}$ ) while $C 2$ and $F 1$ are not extended and cannot get rid of the limit of ferrite grain because lack of energy.

(e) $N=250,008$ cycles, $C 1$ continues to grow strongly to a length of $171.117 \mu \mathrm{m}$. And now $C 2$ has got rid of the limit of ferrite grain with the crack tips break through the boundary. The length of $C 2$ has reached to $89.775 \mu \mathrm{m}$. There is a phenomenon that should be noticed that $C 1$ and $C 2$ have a tendency to merge which will be combined to the DESFC. $F 1$ does not grow either.

(f) $N=300,014$ cycles, $C 1$ and $C 2$ have combined to a new crack, the DESFC $C 1$, and its length now is $647.887 \mu \mathrm{m}$. And the crack $F 1$ which grew slowly before has a large growth to the length of $83.281 \mu \mathrm{m}$. Perhaps the limit of ferrite grain boundary has been broken. Below the left of $C 1$ 's crack tip, there is a new crack $F 2$.

(g) $N=350,040$ cycles, $C 1$ has formed to the traditional long crack, and with the accumulation of damage, $C 1$ continues to grow, but its growth path is not a straight line because the inclusions and other obstacles may influence the growth process. In general, the growth of $\mathrm{Cl}$ is along the direction perpendicular to the stress. Although the crack tips 
are still limited by the ferrite grain boundary or grain, their limiting effect is insufficient to limit the growth of the dominant effective short fatigue crack. And two new cracks $F 3$ and $F 4$ can be seen in the field of view. Besides, the growths of $F 1$ and $F 2$ are greatly suppressed by the predominance of DESFC so that both of them stop growing.

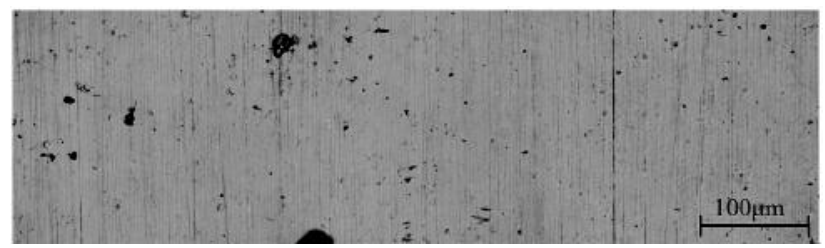

$\mathrm{a}$

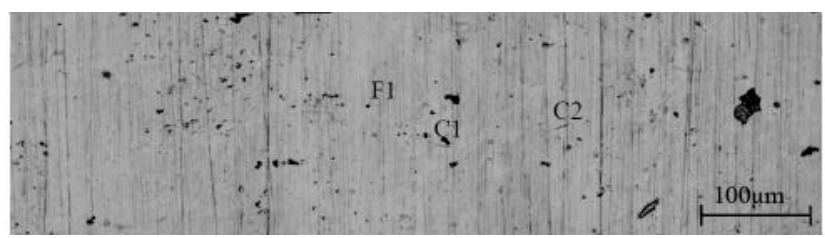

b

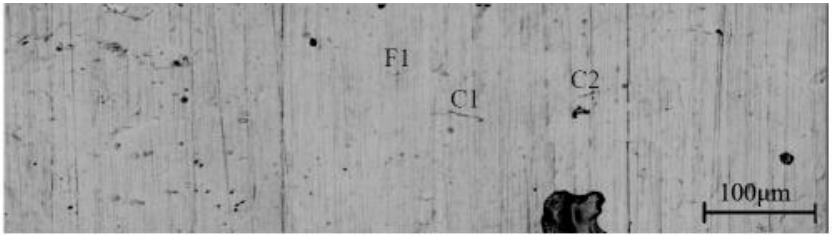

c

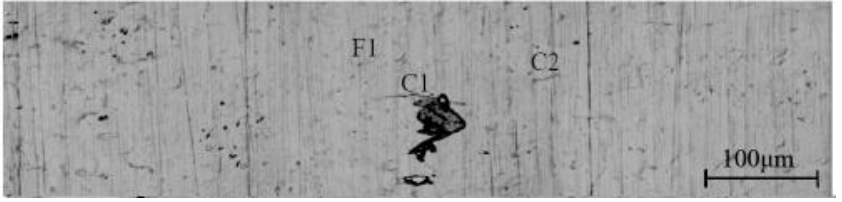

d

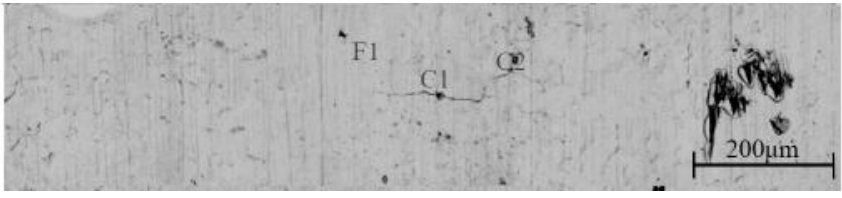

$\mathrm{e}$

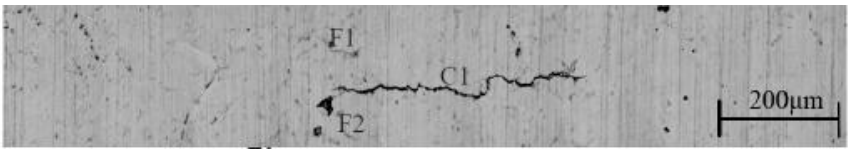

f

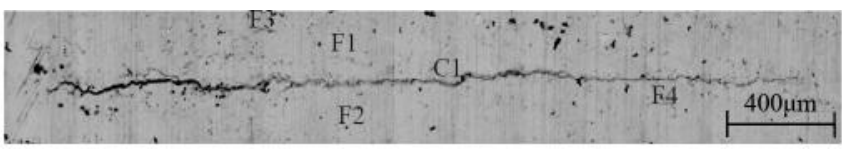

g

Fig. 3. OM images of replica films of fatigue short crack initiation and propagation for typical specimen under rotating-bending cyclic load. 
2.2. Observation of Fatigue Fracture. Figure 4 shows some scanning electron microscope (SEM) images of different areas of the fatigue fracture for typical specimen B-2 with different magnification. As displayed, Fig. 4a shows the full view of the fracture and the crack initiation lies in the bottom left corner of the view which begins from the specimen surface while the fatigue final rupture region is located opposite with a deflection angle. Figure $4 \mathrm{~b}$ shows the fatigue source zone and crack growth zone at low magnification and fatigue striations appearance sourced from crack initiation can be observed. These striations represent the propagation of the short crack. Figure $4 \mathrm{c}$ shows the secondary cracks in crack growth zone at high magnification which are approximately perpendicular to the direction of the crack growth path. And many tear dimples can be seen obviously in transient breaking zone in Fig. 4d.

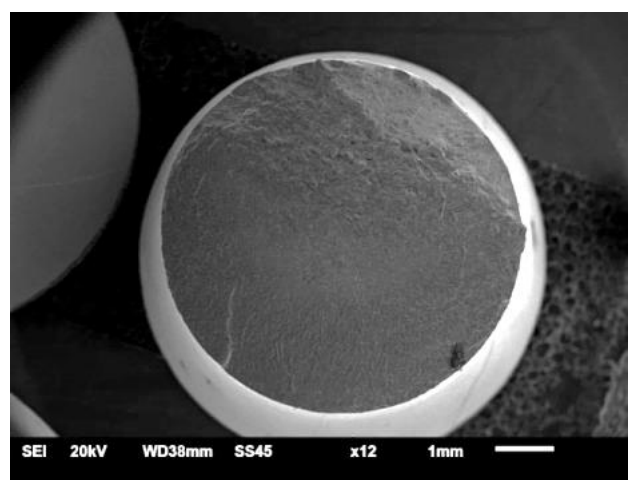

a

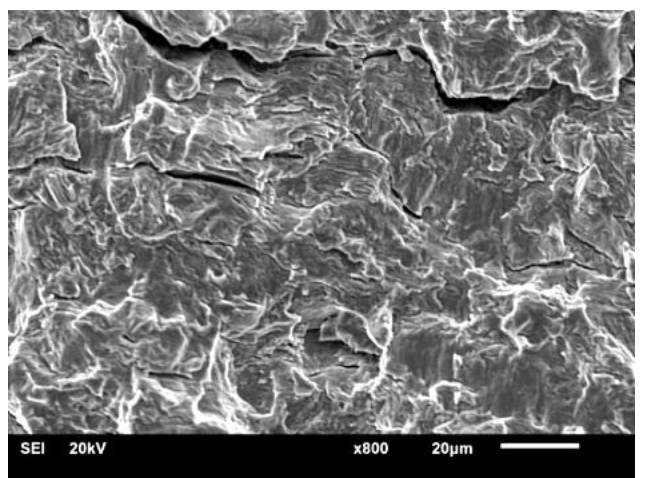

$\mathrm{c}$

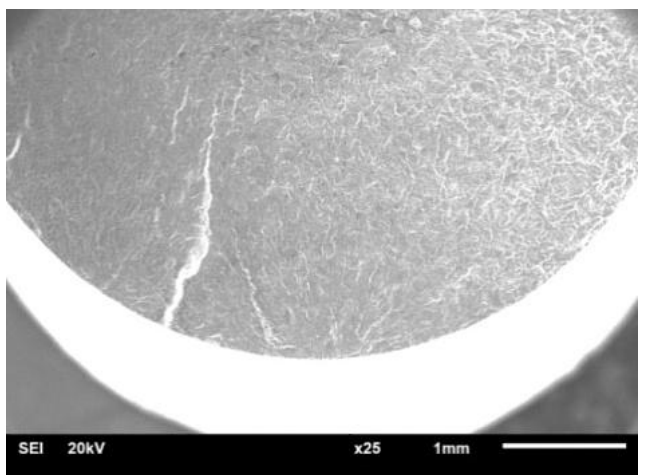

b

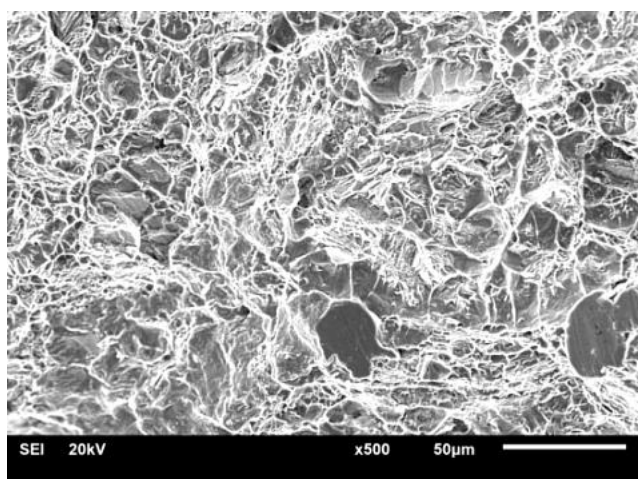

d

Fig. 4. SEM images of fatigue fracture for typical specimen under rotating-bending load.

2.3. Analysis of Typical Specimens. The relationship between the DESFC length and its fatigue life share of three typical specimens B-2, B-4, and B-5 is depicted in Fig. 5, while Figs. 6 and 7 show the variation of DESFC growth rate with the crack length and fatigue life share under rotating-bending load. Taking specimen B-2 as an example, and combining with images of replica films (Fig. 3) and SEM images of fatigue fracture (Fig. 4), the following conclusions can be drawn:

In the whole fatigue life of the specimen, the length of DESFC increases with the number of load cycles without any stagnation (Fig. 5). During the first half the fatigue life, DESFC grows quite slowly, resulting in that the change of DESFC length in the first $50 \%$ life is just $2.1 \%$ of the change of DESFC length in the last $50 \%$ life. In other words, most of the fatigue life is consumed in the crack initiation phase. During the whole process, the 
crack growth rate increases with fluctuations, but it clearly exhibits two decelerations. As seen from Figs. 6 and 7, the data indicate that when the first deceleration of the growth rate happens, its corresponding life share is 0.014 and the corresponding projection length of DESFC is $14.149 \mu \mathrm{m}$, which is close to the equivalent diameter of the ferrite grain. The ferrite grain boundary acts as a barrier because the adjoining pearlite has much higher microhardness. This phenomenon occurs in the stage $b \sim c$ in Fig. 3. When the second deceleration of the growth rate happens, its corresponding life share is 0.411 and the corresponding projection length of DESFC is $75.133 \mu \mathrm{m}$, which is close to the average spacing of pearlite banded structure. Also because of the higher hardness, the layered pearlite banded structure appears another barrier for the crack to overcome. This phenomenon occurs at stage $\mathrm{d} \sim \mathrm{e}$ in Fig. 3. With these analyses, the conclusion can be drawn that the growth of short fatigue crack will influence by the ferrite boundary and the pearlite banded structure and when breaking these barriers, the growth rate of short fatigue crack will decrease and then rise again when breaking through the barriers.

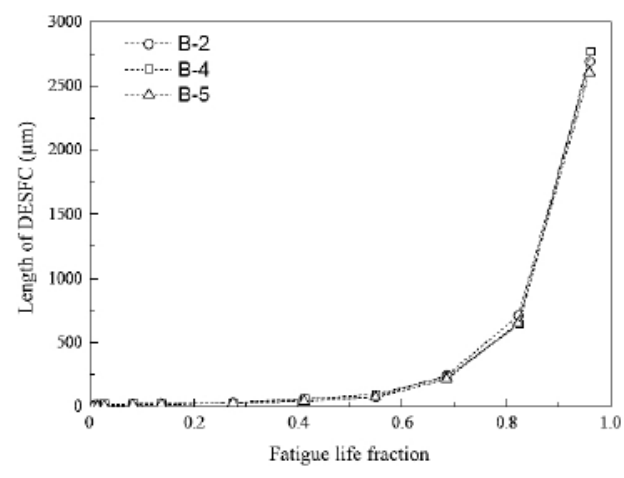

Fig. 5

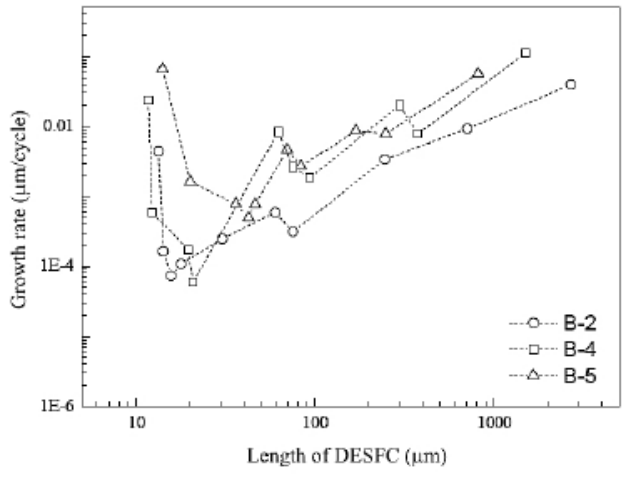

Fig. 6

Fig. 5. Variation curve of DESFC scales with life share for typical specimens.

Fig. 6. Variation curve of DESFC growth rate with DESFC length for typical specimens.

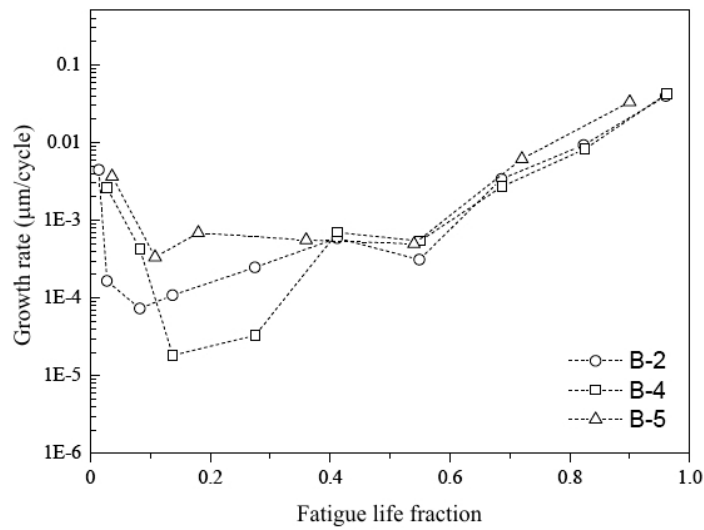

Fig. 7. Variation curve of DESFC growth rate with life share for typical specimens.

Generally speaking, the overall trend of the curves showed in Figs. 5-7 for these three specimens is consistent, but due to the inherent difference of individual characteristic microstructural sizes, these curves do not overlap with each other completely. When the deceleration occurs, the corresponding DESFC length and life share are somewhat dispersed. 
3. Statistical Analysis. In order to determine the reasonable assumed discriminations and the statistical evolution of short fatigue crack behavior for LZ50 axle steel under rotating-bending cyclic load, authors [12] proposed a unified linear regression method, which includes the following three aspects: (i) the total fitting effect which measured with a uniform parameter by quantitative analysis and the best will be selected; (ii) the consistency with the relevant fatigue physics (e.g., when fitting the crack length, the longer the crack, the higher the probability of failure); (iii) the safety of design evaluation. The two characteristic parameters, statistical evolution of DESFC length and life share, have been analyzed in this study by comparing six commonly used distributions, including three-parameter Weibull distribution (3PWD), two-parameter Weibull distribution (2PWD), normal distribution (ND), lognormal distribution (LND), extreme minimum distribution (EMVD1), and extreme maximum distribution (EMVD2).

3.1. The Statistics Evolution of DESFC Length. The mean value $\left(A_{m}\right)$, standard deviation $\left(A_{S}\right)$, and variation coefficient $\left(V_{A}\right)$ of DESFC length are given in Table 1. As for the total fitting effect, the closer the absolute value of linear correlation coefficient, namely $\left|R_{X Y}\right|$, gets to one, the better the fitting effect is [12]. By comparison, it is found that among the 10 groups of DESFC length data listed in Table 1, EMVD1 has the best fitting effect for 6 groups. Then considering the safety of design evaluation, reference [12] defines two parameters, $d_{F 1}$ and $d_{F 2}$, to reflect the prediction deviation. For EMVD1, 5 groups of data show that $d_{F 1}<d_{F 2}$ and 9 groups of data show that $d_{F 1}<1$, which means that the predicted values will be relatively conservative and safe. At the same time, the EMVD1 conforms to the correlation with the relevant fatigue physics, i.e., with the increase of the growth rate, the failure probability will also increase. In conclusion, EMVD1 shows a better consistency with the criteria described in study [12] than other five distributions, and therefore is a good fit of the DESFC length. Corresponding cumulative distribution curve is shown in Fig. 8a. With the increase of the life share, the length of DESFC increases and the curve of variation coefficient are sine-shaped which fluctuates up and down at 0.3 and reaches the minimum when the life share is 0.9. So there is a large scatter of the DESFC length and the growth of DESFC is not stable at all stages.

$\mathrm{T}$ a b 1 e 1

Basic Statistical Parameters of DESFC Length under Rotating-Bending Load

\begin{tabular}{||c|c|c|c||}
\hline$f$ & $A_{m}, \mu \mathrm{m}$ & $A_{s}, \mu \mathrm{m}$ & $V_{A}$ \\
\hline 0.1 & 20.431 & 5.918 & 0.290 \\
\hline 0.2 & 28.006 & 9.066 & 0.324 \\
\hline 0.3 & 36.122 & 13.396 & 0.371 \\
\hline 0.4 & 58.164 & 18.573 & 0.319 \\
\hline 0.5 & 99.703 & 40.265 & 0.404 \\
\hline 0.6 & 185.570 & 74.144 & 0.400 \\
\hline 0.7 & 328.607 & 91.306 & 0.278 \\
\hline 0.8 & 814.433 & 294.689 & 0.362 \\
\hline 0.9 & 1797.381 & 273.352 & 0.152 \\
\hline 1.0 & 2986.122 & 636.993 & 0.213 \\
\hline
\end{tabular}


T a b 1 e 2

Basic Statistical Parameters of Fatigue Life under Rotating-Bending Load

\begin{tabular}{|c|c|c|c|}
\hline $2 a, \mu \mathrm{m}$ & $f_{m}$ & $f_{s}$ & $V_{f}$ \\
\hline 20 & 0.1080 & 0.0686 & 0.6354 \\
\hline 50 & 0.3746 & 0.0749 & 0.1999 \\
\hline 100 & 0.5091 & 0.0725 & 0.1424 \\
\hline 150 & 0.5747 & 0.0570 & 0.0992 \\
\hline 300 & 0.6789 & 0.0520 & 0.0766 \\
\hline 500 & 0.7536 & 0.0251 & 0.0333 \\
\hline 700 & 0.7917 & 0.0397 & 0.0501 \\
\hline 800 & 0.8023 & 0.0372 & 0.0464 \\
\hline 900 & 0.8127 & 0.0349 & 0.0429 \\
\hline 1000 & 0.8230 & 0.0337 & 0.0409 \\
\hline 1500 & 0.8692 & 0.0273 & 0.0314 \\
\hline 2000 & 0.9041 & 0.0175 & 0.0194 \\
\hline
\end{tabular}

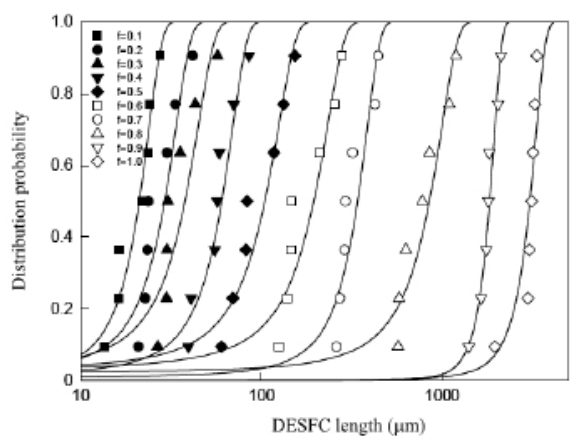

a

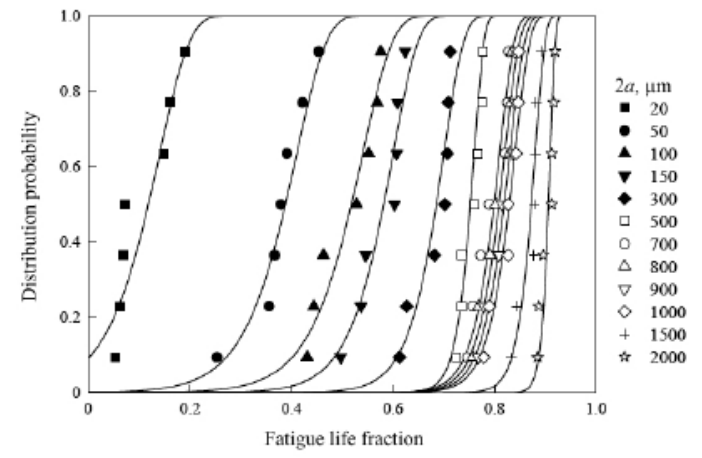

$\mathrm{b}$

Fig. 8. Extreme minimum value distribution probability curves of DESFC length (a) and fatigue life share (b).

3.2. The Statistics Evolution of Fatigue life share. The mean value $\left(f_{m}\right)$, standard deviation $\left(f_{s}\right)$, and variation coefficient $\left(V_{f}\right)$ of fatigue life share are given in Table 2 . The statistics evolution of fatigue life share is analyzed using the same approach as described above. It is found that among the 12 groups of life share data, EMVD1 has the best fitting effect for 5 groups of data, while 11 groups of data show that $d_{F 1}<d_{F 2}$. Besides, just as mentioned in Subsection 3.1, EMVD1 conforms to the consistency with the relevant fatigue physics. It can be concluded that EMVD1 is a good assumed distribution of fatigue life share. Corresponding cumulative distribution curve is shown in Fig. 8b. With the increase of DESFC length, the fatigue life share increases, while the variation coefficient decreases constantly from 0.635 , then stabilize for a certain period of time, and eventually tend to zero. So, initially, a large dispersion of the fatigue life share is observed, which gradually exhibit a saturation and approach zero. 
4. Short Crack Growth Model. To refine the short fatigue crack growth concept and analyze it quantitatively, it is necessary to establish the short crack growth model. Based on the foregoing study, it can be confirmed that the behavior of short fatigue crack for LZ50 axle steel under rotating-bending cyclic load is mainly controlled by the material microstructure. Given this, the short fatigue crack growth model of Yang et al. [13, 14], which accounts for various microstructure barriers, was selected as follows:

$$
\frac{d a}{d N}=G_{0}+A\left[\Delta W_{t} a-\Delta W_{t} \sum_{i=1}^{n} f_{i}\left(\Delta d_{i}\right) d_{i}\right]^{m},
$$

where $a$ is DSSEC length, $N$ number of cycles, $G_{0}$ is the basic growth rate in each microstructure and, in general, it is the minimum value of growth rate in the first microstructural barrier period, $\Delta W_{t}$ is the far field total cyclic strain energy density, $d_{i}$ is the length of characteristic microstructural barrier, $i$ is the subscript to clarify the kinds of barriers, $A$ and $m$ are constants relating to materials, and $f\left(\Delta d_{i}\right)$ is the resistance coefficient function.

The microstructure barriers of LZ50 axle steel in this study are reduced to only two types, which are the ferrite grain boundary and the pearlite banded structure. When conducting the replica tests, the nominal stress on the surface of the specimen is controlled, so the far field total cyclic strain energy density $\Delta W_{t}$ can be expressed by constant in the respective equation. Given this, the simplified models take the following forms:

$$
\begin{aligned}
& \frac{d a}{d N}=G_{01}+A_{1}\left[a-f_{1}\left(\Delta d_{1}\right) d_{1}\right]^{m_{1}}, \\
& \frac{d a}{a N}=G_{02}+A_{2}\left[a-f_{2}\left(\Delta d_{2}\right) d_{2}\right]^{m_{2}},
\end{aligned}
$$

where $d_{1}$ is the equivalent diameter of ferrite grains and $d_{2}$ is average spacing of banded pearlite structures.

T a b 1 e 3

Parameters of Short Fatigue Crack Growth Model Considering All Valid Specimens

\begin{tabular}{|c|c|c|c|c|c|}
\hline \hline Parameter & $d_{1}, \mu \mathrm{m}$ & $G_{01}, \mathrm{~m} /$ cycle & $A_{1}$ & $m_{1}$ & $\alpha_{1}$ \\
\hline Value & 23.64 & $7.08 \cdot 10^{-11}$ & $6.33 \cdot 10^{-9}$ & 2.52 & 0.55 \\
\hline Parameter & $d_{2}, \mu \mathrm{m}$ & $G_{02}, \mathrm{~m} /$ cycle & $A_{2}$ & $m_{2}$ & $\alpha_{2}$ \\
\hline Value & 76.00 & $4.19 \cdot 10^{-10}$ & $7.62 \cdot 10^{-11}$ & 1.19 & 0.43 \\
\hline
\end{tabular}

Based on the seven sets of effective test data obtained from the replica tests, all required characteristic parameters of the growth model were obtained and listed in Table 3 . The respective fitting curve is depicted in Fig. 9 and is coincident with most of the test data points, which means the overall fitting effect is good and the two evident decelerations are exhibited correctly. Furthermore, the statistical processing of the test data yields that the short crack growth rate at the early stage has a large scatter because of strong microstructure effect, which scatter diminishes at the later stage, when a long crack is formed. 


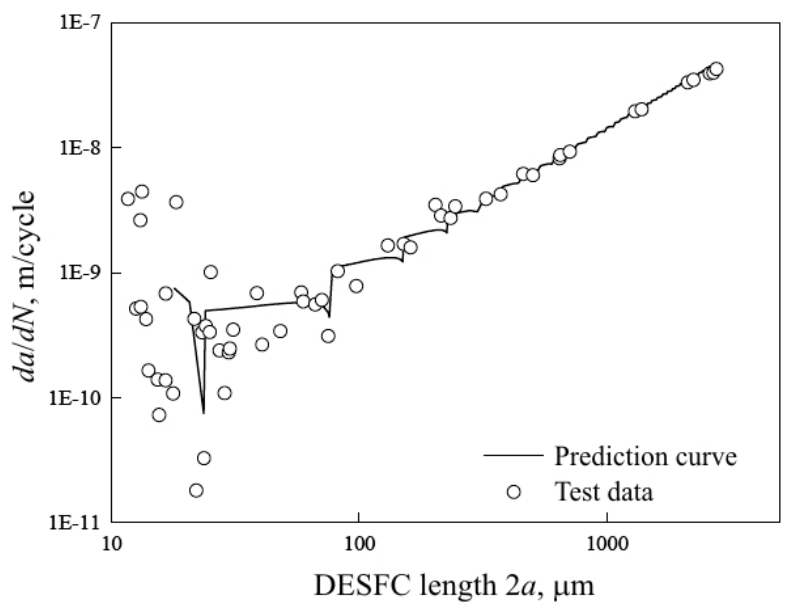

Fig. 9. Fitting curve of short fatigue growth model for all valid specimens under rotating-bending cyclic load.

\section{Conclusions}

1. Under the rotating-bending cyclic load, short fatigue cracks in LZ50 axle steel mainly originate in the ferrite grain boundary or within the ferrite grains, and their growth is strongly influenced by the material microstructure. The overall growth rate of short fatigue crack increases, but there are two typical decelerations because of the limit of the ferrite grain boundary and the banded pearlite structure. As soon as the short fatigue crack breaks the barrier of the banded pearlite structure, its growth behavior coincides with that of long cracks and complies with LEFM.

2. The initiation of short fatigue cracks takes the major part of the total fatigue life because the DESFC length augmentation in the first half of life is about $2.1 \%$ of that in the second half.

3. Both characteristic parameters (DESFC length and fatigue life share) grow in the loading process and have large scatters, which are best-fitted via EMVD1 distribution.

4. Based on the short fatigue crack growth model, which accounts for multiple microstructure barriers, the calculated were effectively fitted with the test data.

Acknowledgments. Present work is supported by the National Key R\&D Program of China (2016YFB1200403), the National Natural Science Foundation of China (51675446 and U1534209), and the Opening Project of State Key Laboratory of Traction Power (grant No. 2015TPL_T13).

1. C. Y. Chen, Fatigue and Fracture [in Chinese], Huazhong University of Science and Technology Press, Hubei (2001).

2. S. Suresh, Fatigue of Materials, Cambridge University Press (1998).

3. Y. S. Hong and B. Fang, "The mesoscopic process and theory of short fatigue cracks initiation and propagation," Adv. Mech., 23, 468-486 (1993).

4. TB/T 2945-1999. LZ50 Axle Railway Vehicle and Steel Billets Technical Conditions, Chinese Standard, Implemented on September 1, 1999.

5. B. Q. Ma, Comparison of Short Fatigue Crack Behavior for LZ50 Axle Steel under Two Different Loading Frequencies [in Chinese], Southwest Jiaotong University, Chengdu (2016). 
6. Y. X. Zhao, Q. Gao, and J. N. Wang, "Experimental observation on the short fatigue crack behavior of a stainless steel pipe-weld metal I - Material microstructures and research approach," Acta Metall. Sin., 36, 931-936 (2000).

7. Y. X. Zhao, Q. Gao, J. N. Wang, "Experimental observation on the short fatigue crack behavior of a stainless steel pipe-weld metal II - Crack initiation, growth and interaction," Acta Metall. Sin., 36, 937-943 (2000).

8. Y. X. Zhao, B. Yang, and Q. Gao, "Initiation and early propagation of short fatigue cracks on weld metal of 1Cr18Ni9Ti pipes," Nucl. Power Eng., 24, 127-132 (2003).

9. Y. X. Zhao, B. Yang, and Q. Gao, "Experiment of physical short fatigue crack propagation of 1Cr18Ni9Ti weld metal," Nucl. Power Eng., 26, 584-589 (2005).

10. Y. X. Zhao, Analysis of Low Cycle Fatigue Short Crack Behavior and Reliability, PhD Thesis, Southwest Jiaotong University, Chengdu (1998).

11. Y. X. Zhao, B. Yang, and Q. Gao. "Equation of short fatigue crack growth law of 1Cr18Ni9Ti weld metal," Nucl. Power Eng., 26, 590-597 (2005).

12. Y. X. Zhao, Y. F. Sun, and Q. Gao, "Unified linear regression method for the analysis of seven commonly used statistical distribution," J. Mech. Strength., 23, 102-106 (2001).

13. B. Yang and Y. X. Zhao, "Experimental research on dominant effective short fatigue crack behavior for railway LZ50 axle steel," Int. J. Fatigue, 35, 71-78 (2016).

14. B. Yang, B. Q. Ma, S. N. Xiao, and Y. X. Zhao, "A probabilistic model for describing short fatigue crack growth behavior of LZ50 steel," Strength Mater., 48, No. 1, 90-97 (2016).

Received 15. 09. 2017 